\title{
EL MOSAICO POLÍCROMO CON DECORACIÓN GEOMÉTRICA DE CÍRCULOS INTERSECANTES DE LA VILLA ROMANA DE BARRUGAT (BÍTEM, TARRAGONA)
}

POR

\author{
RAMÓN JÁRREGA DOMÍNGUEZ \\ Escuela Española de Historia y Arqueologia. CSIC. - Roma
}

\section{RESUMEN}

Presentamos aqui un nuevo mosaico policromo hallado en una villa romana situada en el lugar llamado Barrugat (Bitem. Tarragona), en Cataluña, cerca de la ciudad de Tortosa. Este mosaico (que fue destruido después de su descubrimiento) se conoce gracias a un dibujo hecho en el año 1911, que habia sido olvidado hasta tiempos recientes.

\section{SUMMARY}

We present here a new polychrome mosaic found in a Roman villa in the place named Barrugat (Bitem, Tarragona), in (atalonia, near the city of Tortosa. This mosaic (destroyed then of its discovery) is known by a drawing made in 1911, forgotten until recent times.

En el año 1910, con ocasión de la construcción del canal izquierdo del río Ebro, se descubrieron en el término de Bítem, muy cerca la ciudad de Tortosa (capital de la comarca catalana del Baix Ebre, en la provincia de Tarragona), los vestigios de una lujosa villa romana. Se pudieron documentar restos de muros, asi como de hipocaustos y un mosaico. Posteriomente, en 1984 se llevó a cabo una campaña de urgencia (todavía inédita) de excavación y limpieza en los márgenes del mencionado canal, sobre la que se ha publicado una primera referencia (Genera-Arbeloa 1986-87, pág. 87), y que dió como resultado el hallazgo de abundante material arqueológico, así como restos de otros mosaicos, que permanecen inéditos.

Los hallazgos cerámicos documentados en los trabajos de 1984 cubren un abanico cronológico que abarca desde época romano-republicana o quizá altoimperial (ello no es seguro considerando que la villa se encuentra junto a un pequeño asentamiento ibérico, del cual eventualmente podrian proceder los materiales más antiguos hallados en el área de la misma) y finales del siglo $\mathrm{V}$ o la primera mitad del VI como mínimo, de acuerdo con los fragmentos de sigillata africana D localizados en este lugar' ${ }^{\prime}$.

En relación a los hallazgos efectuados a principios de siglo existe una breve referencia del arquitecto Joan Abril i Guanyabens (1931, págs. 33-34), que describe someramente la naturaleza de los mismos. Sin embargo, no se conocia ningún detalle sobre el mosaico al cual hace referencia este autor. Recientemente, con ocasión de una revisión de los fondos del Museo Municipal de Tortosa se halló un dibujo realizado por el mismo Abril y fechado en el año 1911 , que representa el mosaico en cuestión. Habida cuenta de que su autor es un arquitecto cabe suponer la exactitud del dibujo en relación al modelo real; Abril tuvo el cuidado de representar incluso las abundantes teselas de que está compuesto el mosaico, y de especificar las dimensiones del mismo, indicando la escala a que está hecho el dibujo e incluyendo varias medidas parciales. Dicho dibujo se encuentra actualmente expuesto en el Museo Municipal de Tortosa?

\footnotetext{
I Para una visión de conjunto sobre el yacimiento de Barrugat véase Genera 1983-84. Asimismo, para un estudio más amplio sobre la fase tardoantigua del mismo véase Járrega, 1993.

2 Agradecemos al personal del Museo de Tortosa las facilidades que en todo momento nos dieron para estudiar este dibujo.
} 
El mosaico en cuestion era de opus tessellatum polícromo; dado que es la única fuente gráfica que tenemos sobre el mismo (puesto que el original ha desaparecido), nos remitiremos al dibujo de Abril siempre que hagamos referencia a su coloración. En conjunto, la representación del mosaico debida a J. Abril produce una impresión de verismo y fidelidad al modelo real, que permite hacer un estudio del mismo basado en datos fiables. Añadiremos que el mosaico cubria un pavimento que descansaba sobre un hipocausto, cuya sección fue asimismo representada por J. Abril junto al dibujo del mosaico (véase figura 1, arriba).

\section{DESCRIPCIÓN DEL MOSAICO}

El mosaico, como se ha dicho, se encontraba situado sobre un hipocausto. Se ignora si servía como pavimento a una habitación o bien a un pasillo o ambulacro, dado que en el dibujo se observa claramente que estaba fragmentado en dos de sus lados, y no es posible, por consiguiente, determinar la extensión primitiva del mosaico; parece ser, por simetria, que el esquema compositivo sería el mismo tanto en la parte documentada como en la que falta. Las dimensiones del fragmento se situarían alrededor de los $112 \times 140 \mathrm{cms}$. (teniendo en cuenta que el mismo no tiene unos límites regulares), según se deduce de las medidas indicadas por Abril. Su escasa anchura permite suponer que pudo corresponder a un ambulacro, o bien debió pavimentar una habitación de reducidas dimensiones, que en tal caso sería bastante estrecha, si bien su longitud es desconocida.

Los colores del mosaico (siempre según el dibujo de Abril) son los siguientes: amarillo, rosa, verde claro (con dos tonalidades, una más pálida que la otra), verde oscuro, marrón claro y marrón oscuro (o quizá negro), éste último reducido a algunas zonas.

La orla del mosaico está formada por líneas de semicírculos secantes y tangentes cuya intersección forma ojivas y escamas, en oposición de colores, siendo las ojivas polícromas. El ejemplo citado en el reciente corpus de mosaicos geométricos (Balmelle et alii 1985, pág.
99. lám. 49, b), hallado en El Djem (Túnez), es muy similar al de Barrugat, aunque en nuestro ejemplar el centro de las ojivas, más oscuro, aparece aislado del punto de contacto entre la cenefa y el campo, a diferencia de lo que ocurre en el mosaico de El Djem. En el interior de estas ojivas, y enmarcadas por un fondo blanco, aparecen dos ojivas concéntricas, de las cuales la exterior es alternativamente de color marrón claro y verde o amarillo claro (no es fácil precisarlo a partir del dibujo de Abril), mientras que la ojiva interior o central es de color verde oscuro; el espacio conformado por los semicirculos secantes, que forma la decoración de escamas, es de color verde oscuro, y está delimitado por una línea de teselas de color verde claro, separada de las ojivas por otra línea paralela de color verde oscuro.

El campo del mosaico está constituido por una composición ortogonal de círculos intersecantes, los cuales dejan entrever cuadripétalos en las intersecciones y forman cuadrados cóncavos en el núcleo de los círculos; presenta teselas de color verde en los puntos de tangencia. Los cuadripétalos resultantes de la intersección de los mencionados círculos están delimitados por teselas de color verde oscuro; el interior de los mismos está decorado con sucesivas líneas en forma de ángulos agudos, alternando sucesivamente los colores marrón claro, verde claro y verde oscuro. Esta decoración del interior de los pétalos es bastante atípica, dado que no conocemos paralelos de la misma; parece derivar de los motivos denticulados que en ocasiones decoran el interior de estos pétalos ( $\mathrm{cfr}$. Balmelle et alii 1985, pág. 371, lám. 237, c).

Los cuadrados cóncavos situados en el centro de los círculos presentan una composición ordenada en lineas de círculos orientadas en diagonal. La descripción de los motivos la realizaremos frontalmente, es decir, que si un motivo puede parecer una cruz siguiendo la línea diagonal en que se ordena, aparecerá como un aspa contemplando frontalmente el mosaico. Es esta última la descripción que utilizaremos. De este modo, los cuadrados cóncavos aparecen visualmente como estrellas rombiformes, aunque respetamos la denominación de cuadrados cóncavos establecida en el mencionado corpus 


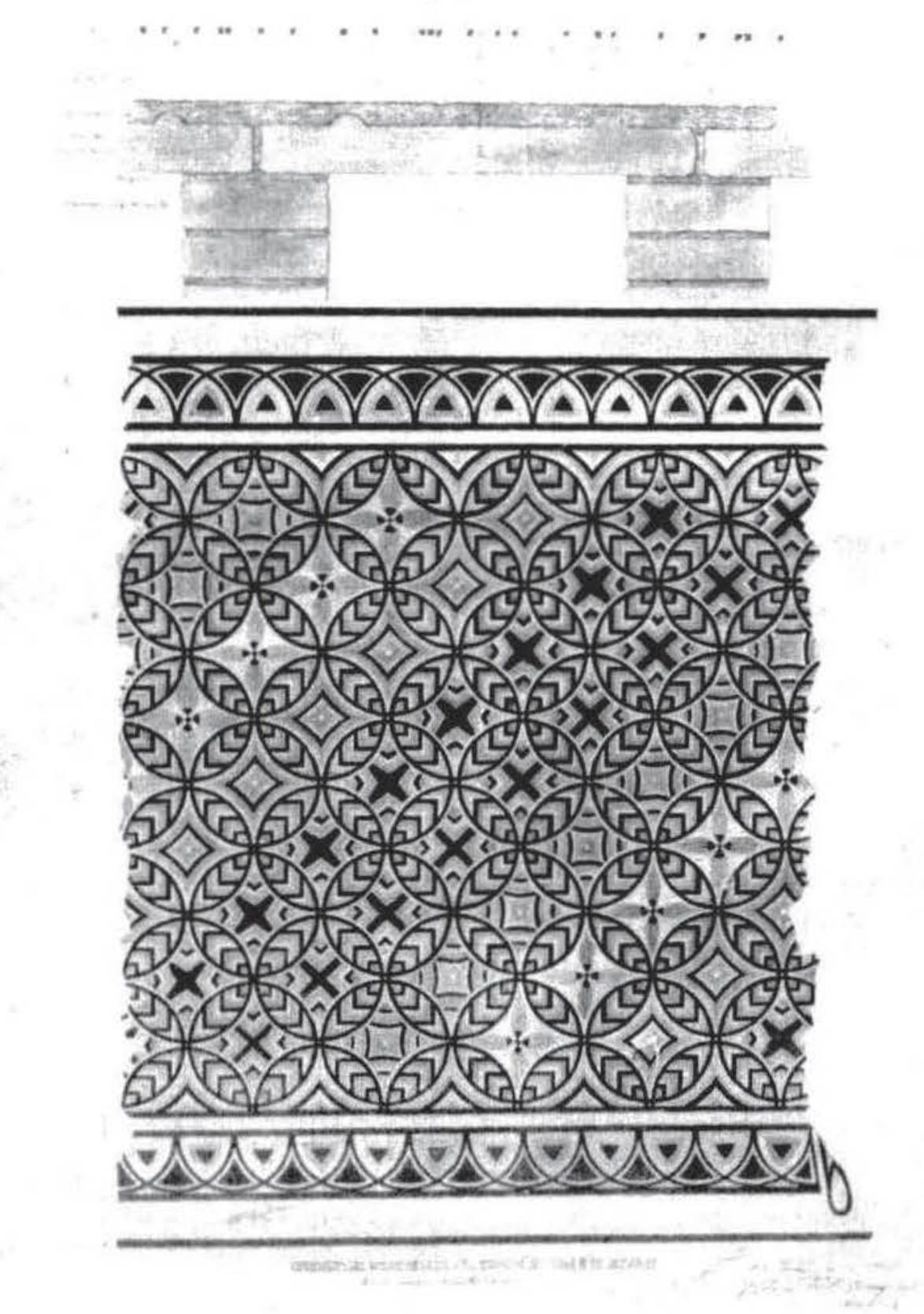

Figura 1-Aspecto del mosaico policromo de la villa romana de Barrugat, según la representación gráfica debida a Joan Abril i Guanyabens, que se encuentra expuesta en el Museo de Tortosa (fotografia Daufi). 
de motivos geométricos (Balmelle et alii 1985 , pág. 371). Cuando hagamos referencia a situaciones a izquierda o derecha nos referiremos a la orientación presentada en el dibujo de J. Abril, del cual se acompaña una fotografia en este trabajo.

Sucesivamente, y de izquierda a derecha. sobre un fondo de color (aparentemente) blanco, se aprecia una flor de cuatro pétalos dispuestos en forma de cruz, cuyo centro está formado por una florecilla de color verde oscuro. La coloración de los pétalos es diferente en cada caso; así, de izquierda a derecha $y$ de abajo a arriba son amarillos en el primer cuadrado, mientras que en el segundo los pétalos verticales son de color rosa, y los horizontales amarillos. El tercer cuadrado cóncavo presenta todos los pétalos de color rosado, mientras que en el siguiente, a la inversa de lo que sucedia en el segundo, los pétalos verticales son amarillos y rosados los horizontales. Se aprecia, pues, una alternancia en la coloración de los pétalos, que son amarillos y rosados con casos intermedios en que la coloración varia según sean los pétalos verticales u horizontales.

En la siguiente alineación, sobre un fondo de color verde claro aparecen unos cuadrados cóncavos concéntricos, formados sucesivamente por líneas de color verde oscuro, verde claro y amarillo, resultando el núcleo formado por un pequeño cuadrado (tal vez una sola tesela) de color verde claro. La parte exterior de los mismos aparece cortada por los cuadripétalos formados por la intersección de los círculos.

En la siguiente alineación de cuadrados cóncavos, sobre un fondo de color verde claro idéntico al anterior, aparecen varias aspas concéntricas (como los cuadrados anteriores, cortadas en su parte exterior por la intersección de los círculos) formadas por líneas sucesivas de color marrón claro, verde oscuro y verde claro; el aspa central, sin embargo, es de color marrón oscuro, o tal vez negro, extremo éste que no puede precisarse a partir del dibujo conservado.

Idénticos en todos los detalles a los que acabamos de describir son los cuadrados cóncavos de la siguiente línea diagonal, con la única diferencia de que el aspa central, del mismo color (marrón o negro) que la anterior, no es rectilinea como la antes citada, sino que presenta un engrosamiento del centro en relación a los extremos.

La alineación siguiente está formada por una serie de cuadrados cóncavos concéntricos, que aparecen como rombos desde el punto de vista que hemos adoptado, a diferencia de lo que ocurría con los de la segunda línea; al contrario que los mismos, por lo tanto, no aparecen cortados por la intersección de los circulos, dado que son paralelos a ellos. Están formados por varias tiras de color verde claro, marrón claro y verde oscuro respectivamente, estando el núcleo formado por un pequeño cuadrado (probablemente una sola tesela), de color verde claro, colocado asimismo en posición romboidal desde nuestro punto de vista. A partir de aqui, la siguiente línea vuelve a mostrar la composición que hemos descrito con relación a la primera, y se va repitiendo sucesivamente la misma composición.

La ordenación de la decoración del campo de este mosaico consiste, pues, en la repetición de un grupo de cinco líneas diagonales de circulos, caracterizadas por los motivos que hemos descrito.

\section{PARALELOS ESTILISTICOS}

La decoración de orlas musivas, consistente en motivos de ojivas y escamas generadas por la intersección de semicirculos secantes y tangentes, se documenta en mosaicos itálicos en blanco y negro desde el siglo II d. C., como muestran diversos ejemplares de Roma y Nápoles (Blake 1936, págs. 83-85, láms. 11.4, 17.1, 25.1 y 39.1). Estos motivos aparecen también en diversos mosaicos del Norte de Africa y de Esparta (Grecia) ${ }^{3}$.

La distribución de este motivo en España ha sido estudiada por Fernández-Galiano (1984, pág. 221), habiéndose documentado en algunos yacimientos de Andalucía y Mérida, así

1 Véase un elenco de estos mosaicos en FernándezGaliano 1984, págs. 219 y notas 3 y 4 , con bibliografia anterior. 
como en Clunia y en diversos yacimientos rurales, como las villae de Cuevas y de Santervás del Burgo, en la provincia de Soria (Fuidio 1934, lám. XV, n. 2; Ortego 1965, pág. 97. fig. 19; Blázquez-Ortego 1983), entre otros. El mosaico de los trabajos de Hércules de Liria (Valencia) (Fernández Avilés 1947, lám. XLVIII), que también presenta este tipo de decoración, no sabemos si corresponde a una villa o a una domus de la ciudad romana de Edeta. De los mosaicos de Can Modolell (Sant Just Desvern, Barcelona) y de la villa romana de El Val (Alcalá de Henares, Madrid) que presentan también este tipo de orla, haremos mención especifica más adelante, dado el estrecho paralelismo compositivo existente entre estos mosaicos y el de Barrugat.

En cuanto a la temática decorativa de los círculos intersecantes, ésta tiene, como es sabido, una amplia cronologia; justo es indicar, sin embargo, que la datación de estas decoraciones es siempre poco precisa, fundamentalmente porque no ha sido posible, en una gran parte de los casos, fecharlas mediante elementos estratigráficos de excavación.

La variante de la temática de círculos intersecantes más sencilla (y probablemente también la más antigua), es la realizada en blanco y negro, en la cual las intersecciones que forman cuadripétalos están hechas con teselas de color negro sobre fondo blanco. Esta temática aparece ya en época severiana, como prueban múltiples ejemplares de las Galias ${ }^{4}$.

En España podemos citar los mosaicos de la villa romana de Torre Llauder (Mataró, Barcelona), datados asimismo en época severiana (Barral 1973, págs. 735 a 742 , y fig. 1 a 10; 1978, págs. 103 a 111 y láms. LVII a LXVIII). Este motivo aparece también en el denominado mosaico «de las Tres Gracias» de Barcelona (Barral 1978, láms. XV a XVIII), y en los de Bell-lloc (Gerona) (Balil 1960), El Puig (Valencia) (Balil 1970, lám. II, n. 3) y Tarragona (Barral-Navarro 1975, lám. II, n. 1), así como en algunos de Mérida (Blanco Freijeiro 1978,

\footnotetext{
4 Pueden consultarse, a este respecto, los diferentes volúmenes del Recueil des mosaïques de la Gaule, publicados como suplementos de la revista Gallia.
}

láms. 28 y 49) y de Andalucia s. Todos estos mosaicos se fechan en el siglo III, sobre todo en época severiana.

Esta temática decorativa perdura, más o menos enriquecida, hasta momentos más tardios. En España se ha documentado en ciudades como Mérida (Blanco Freijeiro 1978, lám. 11), Lugo (Acuña 1973, fig. 7), Clunia (Taracena 1946 , fig. 7) y La Alcudia de Elche (Ibarra 1879 , lám. XXIII), $\mathrm{y}$ en las villae de Liédena (Navarra) (Mezquíriz 1956, láms. XIV-XV), Santervás del Burgo (Soria) (Ortego 1965, fig. 19; Blázquez-Ortego 1983), La Olmeda (Pedrosa de la Vega, Burgos) (Palol-Cortés 1974, fig. 11), Gárgoles de Arriba (Guadalajara) (Fernández-Galiano 1984, pág. 222) ` y Camino Viejo de las Sepulturas (Balazote, Albacete) (Sanz 1987; Blázquez-López MonteagudoNeira-San Nicolás 1989, págs. 40-41 y láms. 12 y 23). Asimismo, se halla presente en otros mosaicos (villae de Can Modolell y El Val) que, por su estrecho paralelismo con el de Barrugat, citaremos más adelante.

La decoración del mosaico de Barrugat presenta una policromía y un barroquismo decorativo que no aparecen en los mosaicos más antiguos con este tipo de decoración. Su paralelismo con otros casos y su datación resultan muy difíciles, basándose solamente en elementos estilísticos; téngase en cuenta que en el variado elenco de ejemplares decorados con temática ortogonal de círculos intersecantes recogidos en el «corpus» sobre las decoraciones geométricas (Balmelle et alii, 1985) no se recoge ningún ejemplar comparable al que aquí nos ocupa.

Un mosaico similar al de Barrugat, tanto por la policromía como por la temática decorativa, fue hallado en la villa romana de Séviac (Montreal, Francia) (Balmelle 1987, págs. 162163 y láms. CII a CIV, n. 287 C). La orla del mosaico la constituyen también lineas de semicírculos secantes y tangentes que forman ojivas y escamas; el campo está formado asi-

\footnotetext{
s Sobre los mosaicos con círculos secantes de Andalucía, véase un elenco en Fernández-Galiano 1984, pág. 222 (con bibliografia anterior).

- Sobre la villa de Gárgoles de Arriba, véase también Sánchez-Lafuente 1986.
} 
mismo por una composición ortogonal de circulos intersecantes que forman cuadripétalos en las intersecciones. Sin embargo, a diferencia del ejemplar de Barrugat, los cuadrados cóncavos formados en el núcleo de los círculos presentan una composición decorativa que no se ordena en diagonal como en el mosaico de Barrugat, sino siguiendo una orientación rectilinea. Así, mientras que en una de las lineas longitudinales aparece un motivo con veinte lados que podría definirse como una cruz inscrita en un cuadrado (aunque sin separaciones internas de ningún tipo, sino formando un mismo motivo), la siguiente línea presenta una flor de cuatro pétalos en cuyo centro aparece un círculo inscrito en un cuadrado. La composición se basa en columnas alternas de círculos con la representación de estos motivos.

Otro mosaico muy cercano en la temática decorativa y en el espacio (y probablemente también en el tiempo), es el hallado en el año 1885 en la masía de Can Modolell (Sant Just Desvern, Barcelona), conocido, como el de Barrugat, tan sólo por un dibujo contemporáneo del hallazgo. Este mosaico ha sido estudiado por Balil (1962) y Barral (1978, págs. 124-125; lám. LXXX, n. 2 a 4). La composición del campo consiste asimismo en círculos intersecantes que forman cuadripétalos en las intersecciones y cuadrados cóncavos en el núcleo de los mismos. En el interior de los citados pétalos se aprecia un motivo floral. Los cuadrados cóncavos presentan un tipo de decoración que acerca este mosaico al de Barrugat, dado que la ordenación de los mismos sigue también un sentido diagonal, representándose alternativamente un nudo de Salomón y una flor de cuatro petálos. Sin embargo, la decoración de la orla difiere parcialmente de la del mosaico que nos ocupa, dado que la línea exterior de ojivas que también tenía el de Can Modolell estaba en este caso separada del campo de círculos intersecantes por una línea de grecas. La coloración del mosaico (blanco, negro, azul, rosa y naranja) difiere parcialmente de la del mosaico de Barrugat.

Un mosaico muy similar al de Barrugat, a pesar de las diferencias que seguidamente señalaremos; se halló en la villa romana de El Val (Alcalá de Henares, Madrid); este mosaico ha sido estudiado por Fernández-Galiano (1984, págs. 217 a 222, láms. (XIII a CXV). Al igual que el de Barrugat, presenta un campo de circulos intersecantes y una orla de ojivas. Esta última está formada por una banda en la cual los espacios de las intersecciones que forman escamas están formados, como sucede en el mosaico de Barrugat, por teselas de color negro, mientras que los que forman las ojivas consisten en un fondo blanco en cuyo interior aparecen otras ojivas de menor tamaño, alternativamente de color rojo y amarillo (FernándezGaliano 1984, pág. 217). Cabe señalar que esta alternancia de colores es la misma ( $\mathrm{si}$ bien el rojo parece ser en este caso marrón claro, según el dibujo de Abril) que se aprecia en el mosaico de Barrugat, aunque en este último, como se ha indicado anteriormente, la parte central de estas ojivas de color alterno está ocupada a su vez por otras ojivas más pequeñas de verde oscuro, a diferencia de las del mosaico de El Val.

La parte central del mosaico de la villa de El Val al que estamos haciendo referencia, si bien está formada por una composición de círculos intersecantes, es bastante diversa de la del mosaico de Barrugat. Las intersecciones de los círculos se alternan oblicuamente en relación a los lados del mosaico, presentando líneas de elipses de color rojo enmarcadas en negro en sentido norte-sur y amarillas enmarcadas en gris en sentido este-oeste; los cuadrados cóncavos están divididos en cuatro partes iguales, cuya coloración se alterna en dos variantes, disponiéndose generalmente dos partes de teselas de color blanco y alternando las dos partes restantes en colores rojo y amarillo. Con ello, los cuadrados cóncavos configuran una disposición de retícula de cuadrados en los cuales quedan inscritos los círculos, lo cual aleja considerablemente esta composición de la del mosaico de Barrugat, pese a la innegable relación tipológica que existe entre ambos.

\section{CRONOLOGÍA}

El aspecto cronológico es el que presenta mayores problemas, dado que carecemos de datos estratigráficos que nos permitan definir- 
lo con precisión. En este caso solamente cabe hacer algunas consideraciones estilisticas y tener en cuenta las fechas atribuidas a otros mosaicos semejantes. Tanto Balil (1962, págs. 6568 ) como Barral (1978, pág. 125) reconocen la frecuencia de los motivos de ojivas y de los circulos secantes, por lo cual atribuyen una datación amplia al mosaico de Sant Just Desvern; mientras Balil propone una cronologia de finales del siglo III o inicios del IV para el mismo, Barral aduce una datación más amplia situada entre finales del siglo II y primera mitad del IV d. C., en base a que la policromía induce a excluir una datación demasiado antigua y a que la composición general le hace descartar una datación posterior a la segunda mitad del siglo IV. Sin embargo, Barral cita una serie de mosaicos (como el de los trabajos de Hércules, en Liria) que presentan decoración de ojivas en la orla, y que considera "par la plupart tardives».

El mosaico antes citado de la villa de Séviac es datado por Balmelle (1987, pág. 163) hacia la segunda mitad del siglo IV. Esta fecha no la atribuye al mosaico per se, sino a todo el conjunto musivario de la villa en general, y lo hace en base a la disposición de las estructuras arquitectónicas de la misma y a las características decorativas de sus mosaicos, a falta de datos estratigráficos (que si existen no se explicitan en dicho trabajo).

La fecha del mosaico de la villa de El Val es también bastante problemática, debido a la simplicidad de su esquema, si bien sus características concretas reflejan, como dice Fernández-Galiano, un gusto por la sobrecarga de los motivos que se manifiesta en mosaicos de los siglos III y IV. El mencionado autor, teniendo en cuenta la irregularidad en la factura de este mosaico (tanto en la variación del motivo de la cenefa como en la disposición de colores en los centros de los cuadrados cóncavos) lo fecha hacia el siglo IV d. C. (Fernández-Galiano 1984, pág. 222).

A pesar de todo cuanto se ha dicho, creemos que cabe hacer hincapié en algunos aspectos que permitirán, a nuestro entender, si no precisar con seguridad la datación del mosaico de Barrugat, si apuntar una cronología proba- ble algo más ajustada. Por un lado, no conocemos paralelos similares de época severiana, periodo en el cual se documentan los círculos intersecantes en blanco y negro pero que en general no parecen confrontables, (incluso en el caso de que sean polícromos), con el barroquismo que aparece en nuestro mosaico. El hecho de que los pétalos formados por la intersección de los círculos estén decorados interiormente por unos motivos anguliformes poco típicos, que creemos derivados de los denticulados que suelen decorar este tipo de pétalos (y que aparecen en el mosaico de Séviac), parece indicar también una evolución de toda esta temática, que no creemos adecuado situar en un momento inicial de este tipo de decoración. Por otra parte, la ordenación decorativa del campo en un sentido diagonal da la impresión de ser, asimismo, un recurso estilístico evolucionado, que no parece documentarse en los mosaicos similares de época severiana.

Creemos, pues, que si bien no es posible descartar totalmente una datación dentro de la primera mitad del siglo III, el mosaico de $\mathrm{Ba}$ rrugat debe situarse cronológicamente en un momento avanzado del mismo o en la primera mitad del siglo IV. En este sentido, además de las cuestiones estilísticas a las que acabamos de hacer referencia, tenemos en cuenta la datación atribuida por Balmelle al mosaico de Séviac, tan semejante al de Barrugat, como hemos visto. Por otro lado, del dibujo de Joan Abril se deduce una clara regularidad en la factura y ordenación de los motivos, que contrasta con el mosaico de la villa de El Val (Alcalá de Henares); por esta razón pensamos que este último mosaico quizás sea más tardío que el de Barrugat, fechándose ya en un siglo IV avanzado.

Como hipótesis de trabajo, suponemos que los mosaicos de Barrugat y Sant Just Desvern podrían corresponder a un momento floreciente para algunas villae de la zona costera catalana situable en torno a la época tetrárquica o constantiniana. En apoyo de esta teoría podemos citar el caso de un mosaico policromo de la villa romana de Darró (Vilanova i la Geltrú, Barcelona), no muy lejos de la de Sant Just Desvern, del cual paradójicamente desconocemos su temática decorativa (debido a haberse 
hallado casi totalmente destruido) pero que ha podido fecharse estratigráficamente en relación a una fase de reconstrucción de la villa que se ha datado en tiempos de Diocleciano (LópezFierro 1987-88, págs. 65-66), y que creemos que podría situarse, bien en esta época o bien en la de Constantino?. Además, aunque se relacione con la citada fase constructiva de la viIla, no debe olvidarse que el mosaico en si podria ser algo posterior a la misma, aunque ello nos parece poco probable.

Además de los casos citados, podemos traer a colación otros diversos mosaicos del siglo IV detectados en diversas villae de la costa catalana, como la de Cal Ros de les Cabres (El Masnou) (Barral 1978, pág. 95) ${ }^{8}$, La Rectoria (Pacs) (Balil 1987, passim) y el hallazgo posiblemente localizado en El Marquet (Mura) (Daura et alii 1987, pág. 85; Daura-Pardo 1990, pág. 146, nota 4; Daura-Pardo 1991, pág. 48, nota 8; Daura 1992, págs. 251-252 y 262, foto 13) en la provincia de Barcelona, y Els Munts (Altafulla) (Navarro 1980) y Paret Delgada (Guitart 1936 y Sánchez Real 1951, passim), en la provincia de Tarragona, todos ellos indicativos de la existencia de asentamientos rurales relativamente ricos ( $\mathrm{y}$ algunos de ellos realmente lujosos, como el de Els Munts) en la costa catalana durante el siglo IV d. C. Los mosaicos de la villa de Els Ametllers (Tossa de Mar, Gerona)

\footnotetext{
7 Según comunicación personal de los excavadores de la villa de Darró (concretamente, del doctor Alberto López y el señor Javier Fierro, a quienes agradecemos esta indicación), la datación en tiempos de Diocleciano la hacen en base a la aparición de la forma más antigua de la sigillata africana D (la Hayes 58) y la ausencia de las otras formas de esta producción en niveles asociados a la construcción del mosaico. Dado que la sigillata africana D comienza a producirse y exportarse principalmente hacia el segundo cuarto del siglo IV, creemos que la presencia de la forma Hayes 58 , que efectivamente comenzó a producirse a finales del siglo III, no impide por otra parte una datación constantiniana para esta fase constructiva de la villa, puesto que la ausencia de la otras formas de la producción cuadra muy bien con este "lapsus» cronológico.

* En la villa de Cal Ros de les Cabres se halló un mosaico policromo con decoración geométrica de circulos que ha sido fechado por Barral en la primera mitad del siglo IV (Barral 1978, págs. 92 y 95), la misma datación que atribuimos al mosaico de Barrugat. Sin embargo, los mencionados círculos del mosaico de Cal Ros no son intersecantes, por lo que tipológicamente dicho mosaico se aleja bastante del mosaico de Barrugat.
}

son más tardios, y podrian tanto datarse en la segunda mitad del siglo IV (Castillo 1939, págs. 254-255) como pertenecer ya al siglo $\mathrm{V}$ d. C. (Járrega, 1993). En el contexto definido por estos yacimientos creemos que debe inscribirse el hallazgo de Barrugat que aquí estudiamos.

\section{CONCLUSIONES}

En definitiva, y aunque podamos conocerlo tan sólo mediante una representación gráfica, el mosaico de Barrugat viene, aunque tardiamente, a engrosar el elenco de mosaicos de la zona Este de la antigua Hispania citerior, concretamente de los polícromos con decoración geométrica. La datación que proponemos, dentro de un margen amplio comprendido entre finales del siglo II / inicios del III y mediados del IV d. C., creemos que debe bascular mejor hacia la segunda mitad avanzada del siglo III o, con preferencia, la primera mitad del IV d. C. En todo caso, la falta de datos estratigráficos y la ambigüedad cronológica de los elementos estilisticos nos impiden precisar más su cronología.

\section{BIBLIOGRAFÍA}

Acuña, F., 1973: Mosaicos romanos de Hispania Citerior II. Conventus Lucensis. Studia Archaeologica, 24. Santiago de Compostela, Valladolid.

AbRIL, GuANyABENS, J., 1931: Un capitol de la meva actuació a Tortosa, Barcelona.

BALIL, A., 1960: Mosaico de Belerofonte y la Quimera de Torre Bell Lloch (Gerona), Archivo Español de Arqueologia, XXXIII, págs. 82-112, Madrid.

BALIL, A., 1962: Mosaicos ornamentales romanos de Barcelona, Archivo Español de Arqueologia, 35, págs. 63-69, Madrid.

BALIL, A., 1963: El poblamiento rural en el «Conventus Tarraconensis», Celticum, IX, págs. 217-228, París.

BALIL, A., 1970: Estudios sobre mosaicos romanos I. Los mosaicos de la villa romana de El Puig de Cebolla (Valencia), Studia Archaeologica, 6, págs. 1-19, Santiago de Compostela. 
BALIL, A., 1987: La villa romana de Pacs (Penedès, Barcelona), Boletin del Seminario de Estudios de Arte y Arqueologia, LIII, págs. 181-189, Valladolid.

Balmelle, C. et alii, 1985: Le décor géometrique de la mosaïque romaine.

Batmelle, C., 1987: Recueil général des mosaïques de la Gaule IV. Aquitaine 2. Gallia. X Suppl., Paris.

BARRAL, X. 1973: Mosaicos romanos de Mataró: la villa de Can Llauder y el edificio de Can Xammar, XII Congreso Nacional de Arqueologia, Jaén 1971 (Zaragoza 1973), págs. 735-746, Zaragoza.

BARRAL, X., 1978: Les mosaïques romaines et médievales de la regio Laietana (Barcelone et ses environs), Barcelona.

Barral, X., y Navarro, R., 1975: Un motivo de orla itálico. Las representaciones de murallas en los mosaicos romanos de Hispania, Boletin del Seminario de Estudios de Arte y Arqueologia, 40-41, págs. 503-522, Valladolid.

BLAKE, M. E., 1936: Roman mosaics of the second century in Italy, Memoirs of the American Academy in Rome, XIII, págs. 67-214, Roma.

Blanco Freijeiro, A., 1978: Mosaicos romanos de Mérida, CSIC, Madrid.

Blazzuez, J. M., y Ortego, T., 1983: Mosaicos romanos de Soria, Madrid.

Blazquez, J. M.; López Monteagudo, G.; Neira, M. L., y San Nicolás, M. P., 1989: Mosaicos romanos de Lérida y Albacete. CSIC, Madrid.

Daura, A., y PARdo, D., 1990: Nous testimonis de la Baixa Romanitat a les conque mitjana i alta del Cardener i el Llobregat, La romanització del Pirineu. 8è Col.loqui Internacional d'Arqueologia de Puigcerdà, págs. 143-151, Puigcerdà.

Daura, A., y Pardo, D., 1991: Restes romanes baix imperials a la conca mitjana-alta del riu Llobregat (noves dades per a un panorama poc conegut), Estrat, 4, págs. 37-59, Igualada.

DAurA, A., 1992: Recull gràfic: Imatges d'arqueologia bagenca pertanyents a l'arxiu de Mn. Santamaria, Arqueologia $i$ patrimoni a la Catalunya interior, «Miscel.lània
d'Estudis Bagencs", 8, págs. 249-265. Manresa.

Daura et alii (Daura, A.; Sánchez, E.; Pardo, D., y Galobart, J.), 1987: El jaciment iheroromà de Boades (Castellgali, Bages), Manresa.

Fernandez Avilits, A., 1947: Mosaico romano procedente de Liria, Adquisiciones del MAN (1940-1945), págs. 113-115, Madrid.

Fernandez-Galiano, D., 1984: Complutum II. Mosaicos, Madrid.

FUIDIO, F., 1934: Carpetania romana, Madrid.

Genera, M., 1983-84: El jaciment de Barrugat: noves dades per al coneixement de la Tortosa d'època romana, Pyrenae, 19-20. págs. 287-288, Barcelona.

Geni:RA, M., y Arbeloa, J. M. V., 1986-1987: L'estat actual de la investigació arqueològica sobre la Dertosa romana $\mathrm{i}$ la seva àrea d'influència, Tribuna d'Arqueologia 19861987, págs. 81-90, Barcelona.

Guitart, J., 1936: Descobriments romans a Paret Delgada, Boletín Arqueológico, III, 5, págs. 137-141, Tarragona.

IBARRA, A., 1879: Illici, su situación y antigüedades, Alicante.

Járrega, R., 1993: Poblamiento y economia en la costa Este de la Tarraconense en época tardorromana (siglos $(V-V I)$ ). Tesis Doctoral, Universidad Autónoma de Barcelona, 1992 (edición en microficha).

LOPEZ, A., y Fierro, X., 1987-1988: Darreres intervencions a l'assentament ibèric $\mathrm{i}$ la vil.la romana de Darró (Vilanova i la Geltrú, Garraf), Tribuna d'Arqueologia 1987-88, págs. 53-68, Barcelona.

Mezquiriz, M. A., 1956: Los mosaicos de la villa romana de Liédena (Navarra), Príncipe de Viana, 62, págs. 9-35, Pamplona.

Navarro, R., 1980: Los mosaicos romanos de Tarragona. Tesis Doctoral inédita, Universidad de Barcelona, Barcelona.

Ortego, T., 1965: Excavaciones en la villa romana de Santervás del Burgo (Soria), Noticiario Arqueológico Hispánico, 3-4, págs. 159-194, Madrid.

PALOL, P. de, y CORTÉS, J., 1974: La villa romana de La Olmeda. Pedrosa de la Vega. Excavaciones de 1969 y 1970. Acta Archaeologica Hispanica, 7, Madrid. 
Sinchiz-Lafuinte, J., 1986: La epigrafia y el entorno arqueológico de la villa romana de Gárgoles de Arriba (Guadalajara), Lucentum, V, págs. 175-182, Alicante.

SAnche: Rfal., J., 1951: Los mosaicos romanos de Pared Delgada, Boletín Arqueológico, 34, págs. 108-109, Tarragona.
SANz, R., 1987: Mosaicos romanos del Camino Viejo de las Sepulturas (Balazote, Albacete), Al-Basit, 21, págs. 43-64, Albacete.

TARACENA, B. 1946: El palacio romano de Clunia, Archivo Español de Arqueologia, XIX, págs. 29-69, Madrid.

\title{
INSCRIPCIONES MUSIVAS EN LA ANTIGÜEDAD TARDÍA HISPANA
}

POR

\author{
JOAN GÓMEZ PALLARÉS
}

Universitat Autónoma de Barcelona

\section{RESUMEN}

Este trabajo revisa y corrige las páginas dedicadas a las inscripciones musivas de Hispania en el libro de M.Guardia, Los mosaicos de la Antigüedad lardia en Hispania. Estudios de iconografia, Barcelona, 1992.

\section{SUMMARY}

This paper tries to revise and correct the pages devoted to Hispania's mosaic inscriptions, contained in M.Guardia's Los mosaicos de la Antigüedad tardia en Hispania. Estudios de iconografia. Barcelona, 1992.

\section{INTRODUCCIÓN}

En el año 1988, la Profesora Milagros Guardia defendía su Tesis Doctoral sobre el tema Temática y programas iconográficos en la musivaria hispano-romana del Bajo Imperio' y hoy nos llega la publicación definitiva de ese trabajo, con el título de Los mosaicos de la Antigüedad tardia en Hispania. Estudios de iconografia ${ }^{2}$. A lo largo de estas páginas quisié-

1 Tesis Doctoral publicada por la Universidad de BarceIona, en su colección de microfichas Tesis Doctorales Microfichadas, n.488, Barcelona, 1989 (ISBN 84-7528-706-9).

2 Publicado por las Promociones y Publicaciones Universitarias, S.A., en Barcelona, 1992 (ISBN 84-7665944-X). ramos presentar algunas observaciones a esta publicación, centrándonos en exclusiva en aquello en que podemos decir algo sólido, es decir, en las inscripciones musivas contenidas en los pavimentos estudiados por la Dra.Guardia ${ }^{3}$. Estas observaciones se van a fijar en el «Apéndice $\mathrm{B}$ » del libro de referencia (págs. 400-412) donde se recogen «las inscriciones que presentan el conjunto de los mosaicos hispánicos del Bajo Imperion. Si es necesario, también nos referiremos a las páginas precedentes donde las inscripciones se estudian en su ambiente arqueológico y edilicio ${ }^{4}$.

${ }^{3}$ En el momento en que escribimos estas páginas (mayo de 1993) se encuentra en curso de publicación nuestro Corpus de Inscripciones Musivas de Hispania (CIMH), que constará de dos secciones diferenciadas. Un primer volumen, que será publicado por la Academia Española de Historia y Arqueología de Roma, se centra en las inscripciones paganas, mientras que una segunda entrega (en formato articulo), trata las inscripciones cristianas.

4 Algunas de estas inscripciones son presentadas en el ámbito de estudios iconográficos sobre los pavimentos figurados de Hispania, que forman la parte importante de este trabajo (págs. 29-293) y que valoro mucho, pero sobre lo que, en conciencia, no puedo hablar: aquello que decia Cicerón, non possumus omnes adire Corinthium. Las inscripciones son citadas también en el "Apéndice A" (págs. 373-399), donde se recoge «el conjunto de viviendas con mosaicos figurados bajo-imperiales que no han sido seleccionados en el estudio previo (pág. 373)m. 